\title{
Erratum to: Fast iterative refinement method for mixed systems of integral and fractional integro-differential equations
}

\author{
Sarah A. Deif ${ }^{1}$. Said R. Grace ${ }^{1}$
}

Published online: 19 July 2017

(C) SBMAC - Sociedade Brasileira de Matemática Aplicada e Computacional 2017

\section{Erratum to: Comp Appl Math DOI 10.1007/s40314-017-0464-7}

In the original publication of the article, a few parts in Eqs. (52) and (53) have been mistakenly typeset. The correct versions of these parts are given below. The original version of the article has been updated with these corrections.

1. The first line in Equation (52) reads

$$
\left|\psi_{n+1}-\psi(x)\right|
$$

It should read

$$
\left|\psi_{n+1}(x)-\psi(x)\right|
$$

2. In Equation (53), the left-hand side of the inequality reads

$$
\left|\psi_{1}(x)-\psi(x)\right|
$$

It should read

$$
\left|\psi_{n+1}(x)-\psi(x)\right|
$$

The online version of the original article can be found under doi:10.1007/s40314-017-0464-7.

\section{Sarah A. Deif}

sarah_deif@hotmail.com; sdeif@cu.edu.eg

1 Department of Engineering Mathematics, Faculty of Engineering, Cairo University, Gamaa Street, Giza 12613, Egypt 